\title{
BLICKDIAGNOSE
}
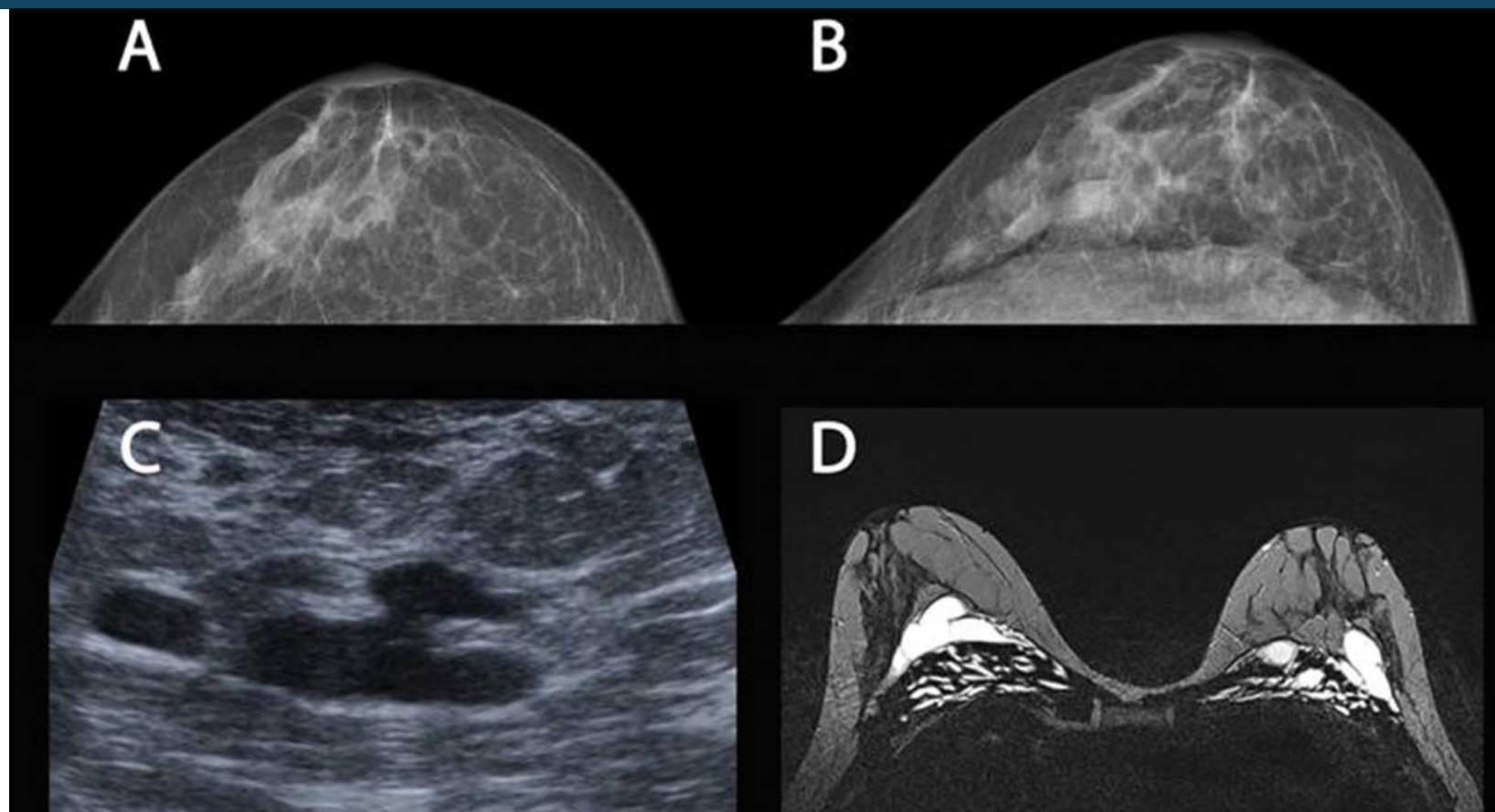

D

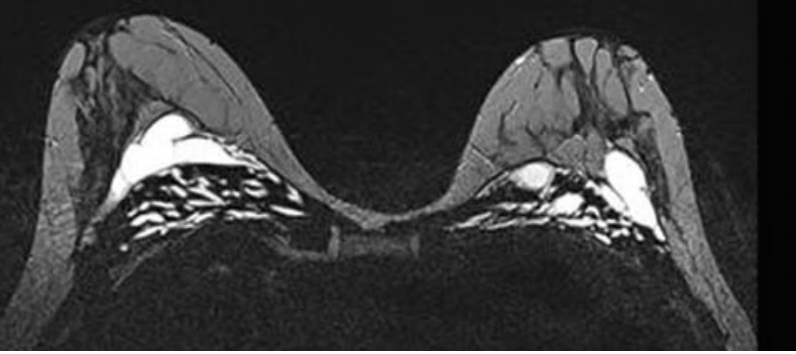

Womit Sie bei der Mammografie rechnen müssen

\section{Überraschende neue „Raumforderungen“ in der Brust}

Eine 54-jährige Patientin nimmt unter Estradiol-Hormonersatztherapie an regelmäßigen mammografischen Früherkennungsuntersuchungen teil. Sie berichtet über seit etwa zwei Monaten tastbare Knoten in beiden Mammae. Im Anamnesebogen werden Operationen verneint.

- In der Mammografie fallen im Vergleich zur Voruntersuchung multiple neu aufgetretene, vermehrt röntgendichte "Raumforderungen" beidseits auf (B im Vgl. mit A). Bei gezielter Nachfrage hinsichtlich stattgehabter Eingriffe an der Brust gibt die Patientin an, dass sie ein halbes Jahr zuvor eine Augmentation beider Mammae mit Hyaluronsäure hat vornehmen lassen.

Aufgrund beidseitiger Mastodynien und dichtem, inhomogenem Parenchym in der Ultraschallbildgebung wird zur weiteren Abklärung eine Magnetresonanz-(MR-) Mammografie durchgeführt. Die Hyaluronsäure-Depots, die zum Teil auch in die Mm. pectorales eingebracht wurden, stellen sich in der Sonografie als zentral echoarme Strukturen dar (C), in der MR-Mammografie als homogen hyperintensis in T2-Gewichtung (D).
Durch eine zunehmende Präferenz und Akzeptanz minimalinvasiver Verfahren wird im Rahmen der Brustkrebsvorsorge in den kommenden Jahren mit einer zunehmenden Anzahl von Patientinnen zu rechnen sein, bei denen eine Augmentation mittels Hyaluronsäure oder anderer injizierbarer Substanzen vorgenommen wurde. Da diese Patientinnen Veränderungen in der Architektur des normalen Drüsengewebes aufweisen, wird die klinische Untersuchung und die Selbstuntersuchung behindert, und eine Früherkennung allein mittels Mammografie ist weniger zuverlässig.

Keywords: mastalgia, mammography, hyaluronic acid

- Dr. med. Martin H. Maurer, Dr. med. Eva Fallenberg Charité - Universitätsmedizin Berlin, Klinik für Radiologie, Campus Charité Mitte, Charitéplatz 1, D-10117 Berlin

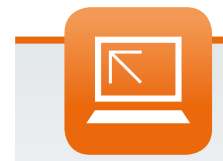

\section{Weitere Infos auf springermedizin.de}

Weitere Blickdiagnosen finden Sie im Internet unter: - http://www.springermedizin.de/blickdiagnose 